\title{
NEUROLOGICAL PICTURE
}

\section{Circumscribed unilateral lower pontine lesion}

A 41 year old woman with no past medical history developed a viral illness 2 weeks before presentation. Five days before presentation she complained of numbness in the left hand and foot, and slight unsteadiness. The following day she had diplopia and a buzzing in the ears that she found difficult to localise. There was no headache. Cranial nerve examination showed a "one and a half syndrome" on testing horizontal eye movements; only abduction of the left eye with nystagmus remained. Trigeminal function including corneal reflex was intact, there was a right lower motor neurone facial weakness, and right sensorineural deafness. The limbs had normal tone and power. There was a slight reduction in proprioception in the left hand, reduced vibration in the left foot, and an extensor left plantar. The clinical findings localised the lesion to the right lower medial side of the pons on the floor of the fourth ventricle, as confirmed on magnetic resonance imaging (MRI) imaging (fig 1). She made a good recovery from her post-viral demyelinating episode following 3 days of intravenous methyl prednisolone.

The diagrammatic representation of the lesion shows the structures involved (fig 2). The lesion incorporates the right medial longitudinal fasciculus, the more ventral pontine paramedian reticular formation, and sixth nerve nucleus causing the "one and a half syndrome", the right facial nerve, trapezoid body (auditory relay centre), and medial lemniscus (above its decussation; minor left dorsal column signs). The only pyramidal sign (corticospinal tract) being an extensor left plantar. Classical syndromes such as Foville's syndrome include a contralateral hemiplegia. ${ }^{2}$

K M Gormley, N J Gutowski Royal Devon and Exeter Hospital and Peninsula Medical School, Barrack Road, Exeter, Devon, EX2 5DW, UK

Correspondence to: K M Gormley, Royal Devon and Exeter Hospital and Peninsula Medical School, Exeter, Devon, UK

\section{References}

1 Daroff RB, Troost BT, Leigh RJ. Supranuclear disorders of eye movements. In: Glaser JS, ed. Neuro-ophthalmology. $2^{\text {nd }}$ ed. Philadelphia: JB Lippincott Company, 1990:299-323.

2 Chusid JG. Correlative neuroanatomy and functional neurology, $17^{\text {th }}$ ed. Los Altos: Lange Medical Publications, 1979:29-31.
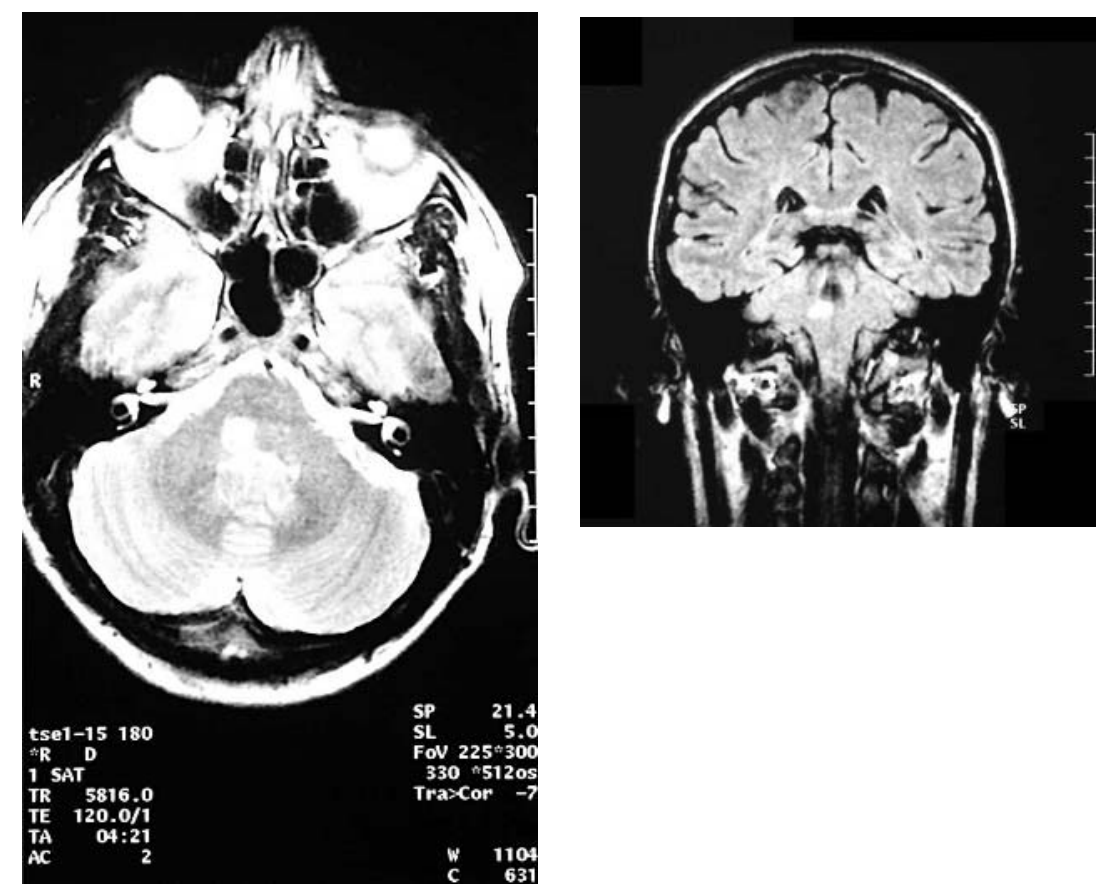

Figure 1 (A) An axial T2 weighted image and (B) a coronal FLAIR sequence showing the lesion in the right lower medial side of the pons on the floor of the fourth ventricle.

Medial longitudinal fasciculus

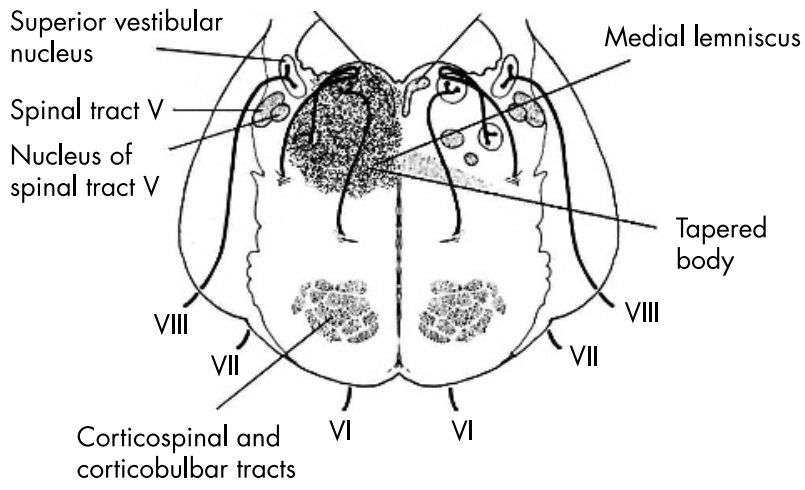

Figure 2 A diagrammatic representation of the lesion showing the structures involved. Adapted from an original illustration. ${ }^{2}$ 